\title{
Interruption of the blood-stage cycle of the malaria parasite, Plasmodium chabaudi, by protein tyrosine kinase inhibitors
}

M.L. Gazarini ${ }^{1}$ and C.R.S. Garcia ${ }^{2}$

\author{
'Departamento de Parasitologia, Instituto de Ciências Biomédicas, and \\ ${ }^{2}$ Departamento de Fisiologia, Instituto de Biociências, Universidade de São Paulo, \\ São Paulo, SP, Brasil
}

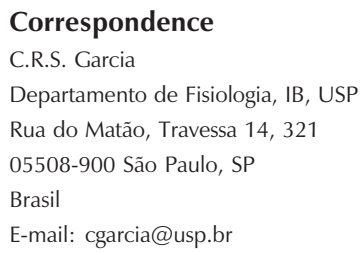

\begin{abstract}
Malaria is a devastating disease caused by a unicellular protozoan, Plasmodium, which affects 3.7 million people every year. Resistance of the parasite to classical treatments such as chloroquine requires the development of new drugs. To gain insight into the mechanisms that control Plasmodium cell cycle, we have examined the effects of kinase inhibitors on the blood-stage cycle of the rodent malaria parasite, Plasmodium chabaudi. In vitro incubation of red blood cells for $17 \mathrm{~h}$ at $37^{\circ} \mathrm{C}$ with the inhibitors led to a decrease in the percent of infected cells, compared to control treatment, as follows: genistein (200 $\mu \mathrm{M}$ 75\%), staurosporine (1 $\mu \mathrm{M}-58 \%), \mathrm{R} 03(1 \mu \mathrm{M}-75 \%)$, and tyrphostins B44 (100 $\mu \mathrm{M}-66 \%)$ and B46 (100 $\mu \mathrm{M}-68 \%)$. All these treatments were shown to retard or prevent maturation of the intraerythrocytic parasites. The diverse concentration ranges at which these inhibitors exert their effects give a clue as to the types of signals that initiate the transitions between the different developmental stages of the parasite. The present data support our hypothesis that the maturation of the intraerythrocytic cycle of malaria parasites requires phosphorylation. In this respect, we have recently reported a high $\mathrm{Ca}^{2+}$ microenvironment surrounding the parasite within red blood cells. Several kinase activities are modulated by $\mathrm{Ca}^{2+}$. The molecular identification of the targets of these kinases could provide new strategies against malaria.
\end{abstract}

During its intraerythrocytic cycle, the malaria parasite, Plasmodium, matures in distinct developmental stages, passing from the ring, through the trophozoite to the schizont form. The molecular events that control these transitions are largely unknown. We have recently reported that the hormone melatonin synchronizes malaria parasites (1) through calcium-mediated signaling. In addition, the parasite is surrounded by a high calcium environment and therefore is able to
Key words

- Malaria

- Plasmodium chabaudi

- Kinase inhibitors

- Signal transduction

- Genistein

- Staurosporin use the ion to signal its intracellular events (2). Kinase activity is largely modulated by calcium and signal transduction pathways. Growth regulation and differentiation in mammalian systems involve protein kinases at many points and in lower eukaryotes, such as Plasmodium, this type of regulatory activity is also thought to occur. The evidence is based on extensive molecular level data since a number of different protein kinases have indeed been identified in Plasmodium spp. 
Kappes et al. (3) have surveyed the known kinase genes of Plasmodium falciparum. These comprise: a) the CMGC group (CLK, MAPK, GSK-3 and CDK families), which includes the family of i) cyclin-dependent protein kinases or CDK-like kinases (CLK), probably involved in cell cycle regulation in malaria. The CLK include PfPK5 (3), Pfmrk (3) and Pfcrk-1 (4); ii) the mitogen-activated protein kinase (MAPK) family, members of which are thought to be involved in regulation of cell proliferation and include PfMAP1 (5); iii) the glycogen-synthase kinase 3 (GSK3) family protein PfPK1 (3). b) Another group of kinases includes the family of protein kinases regulated by $\mathrm{Ca}^{2+}$-calmodulin kinase (CAMk), namely PfCDPK1 (6), PfCDPK2 (7), PfKIN (3), and PfPK2 (8). c) The AGC group (cyclic nucleotide-dependent enzymes) includes protein kinase A (PKA; 9), PKG and PKC.

The question then arises: to what extent does phosphorylation control the parasite's developmental cycle? Although the functional roles of the proteins phosphorylated by these kinases in Plasmodium are not yet known they may clearly be involved in intracellular signaling, since protein phosphorylation regulates many cellular processes. In addition to phosphorylation events reported in malaria parasites, it has been suggested that the selective phosphorylation of red blood cell (RBC) membrane proteins by Plasmodium kinases may modulate several changes in the host cell (10), which accompany the intraerythrocytic development of the parasite, for example diminished membrane deformability.

Many of the erythrocyte membrane proteins undergo reversible phosphorylation, including a tyrosine phosphorylation of the integral membrane protein, band 3. While there is as yet no evidence for a direct role of protein phosphorylation in modulating events in malaria parasites, a red-cell protein phosphorylation process appears to play a part in invasion of the cell by P. falciparum (11).
On this basis, we have determined the effects of protein tyrosine kinase inhibitors on the intraerythrocytic development of $P$. chabaudi.

P. chabaudi (F IP-Pc1 clone) parasites were maintained in female mice (BALB/c strain) by weekly transfer. For inhibition assays, blood with parasites synchronized at the trophozoite stage and with $5-15 \%$ parasitemia was collected from the mice and the red cells were washed twice by centrifugation at $1500 \mathrm{~g}$ for $5 \mathrm{~min}$ in RPMI. The cells were resuspended at $10 \%$ hematocrit in RPMI 1640 (Gibco-BRL, Grand Island, NY, USA), supplemented with $10 \%$ calf serum (GibcoBRL), $40 \mathrm{mg} / \mathrm{l}$ gentamicin, $50 \mathrm{mg} / \mathrm{l}$ hypoxanthine, $5.94 \mathrm{~g} / \mathrm{l} \mathrm{HEPES}$ and $4.2 \mathrm{ml}$ of 5\% $(\mathrm{w} / \mathrm{v})$ sodium bicarbonate for $\mathrm{pH}$ adjustment to 7.4 in $100 \mathrm{ml}$ of medium. Aliquots of 200 $\mu \mathrm{l}$ were dispensed into 96-well plates and incubated with kinase inhibitors for $17 \mathrm{~h}$ at $37^{\circ} \mathrm{C}$. Inhibition of parasite development was assessed by counting the infected RBC per 1000 RBC on methanol-fixed, Giemsastained smears.

The kinase inhibitors, staurosporine, genistein, tyrphostin B44, and tyrphostin B46 were from Calbiochem-Novabiochem Ltd. (Nottingham, UK) and R03 was a gift from Hoffman LaRoche (Basel, Switzerland). Dimethylsulfoxide was used as the solvent for stock solutions of the kinase inhibitors and solvent blanks were performed as controls. The assays were used with $2 \%$ dimethylsulfoxide in the final volume. After $17 \mathrm{~h}$ in culture, the erythrocytes showed the same viability as the control and parasitemia was increased.

All experiments were carried out with at least three different cell preparations.

We attempted to define the importance of phosphorylation events in the intraerythrocytic growth cycle of $P$. chabaudi by examining the effects of several protein kinase inhibitors. Genistein (12), tyrphostin and R03 are generally considered to be selective inhibitors of protein tyrosine kinases, and stau- 
rosporine is a serine/threonine kinase inhibitor (13).

Figure 1A shows the effect of genistein on the $P$. chabaudi parasite cell cycle. Addition of $20 \mu \mathrm{M}$ genistein decreased parasitemia by $33 \%$ relative to control, while at $200 \mu \mathrm{M}$ the parasitemia was reduced by $75 \%$. Figure $1 \mathrm{~B}$ shows that $1 \mu \mathrm{M}$ staurosporine reduced the initial parasitemia by $58 \%$ of the control level. The kinase inhibitor R03 (Figure 1C) at a concentration of $1 \mu \mathrm{M}$ reduced the parasitemia by $75 \%$ of the control level. Two inhibitors of another class, the tyrphostins, also showed activity, though within a higher concentration range. Figure 1D shows that tyrphostin B44 at 100 and 200 $\mu \mathrm{M}$ concentration reduced parasitemia by 66 and $79 \%$ of the control level, respectively. Similarly, tyrphostin B46 at 100 and $200 \mu \mathrm{M}$ concentration reduced parasitemia by 68 and $83 \%$ of control, respectively (Figure 1E).

Studies on signal transduction pathways in malaria parasites have implicated several genes in the control of parasite growth and differentiation (3). Sequencing of these genes identified their products as adenylyl cyclase (14), calmodulin (15) and an E-F hand $\mathrm{Ca}^{2+}$ binding protein (16). Recent studies on calcium dynamics of malaria parasites have indicated similarities to calcium regulation in mammalian cells (17). Briefly, these studies include the existence of a thapsigarginsensitive pool in the human malaria parasite, $P$. falciparum, and in the rodent parasite, $P$. chabaudi (18). In addition to the endoplasmic reticulum calcium pool, the existence of acidic calcium pools in both parasites indicates that they possess multiple mechanisms of calcium storage during their intraerythrocytic developmental stage (18).

The data reported above imply that the modulation of physiological events in Plasmodium must require changes in $\mathrm{Ca}^{2+}$ concentration as well as activation of kinases in an orchestrated manner. This correlation is indicated by the presence of $\mathrm{Ca}^{2+}$-dependent protein kinases, such as PfCDPK1 (6), PfCDPK2

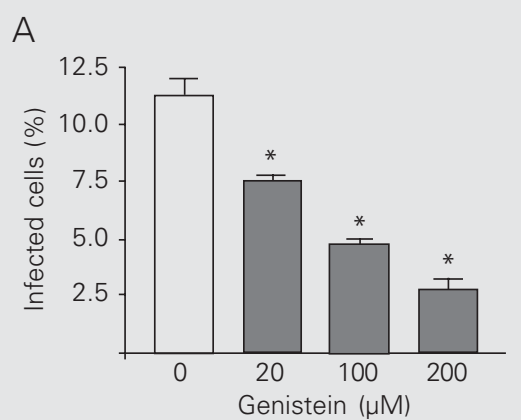

B

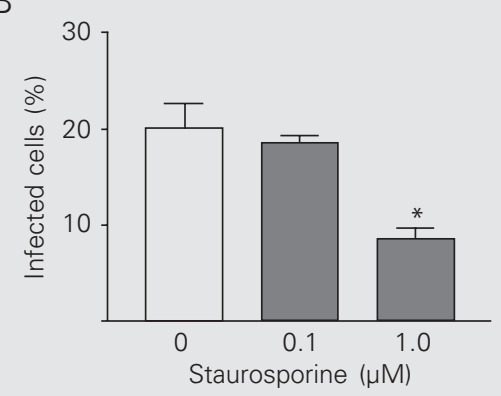

C

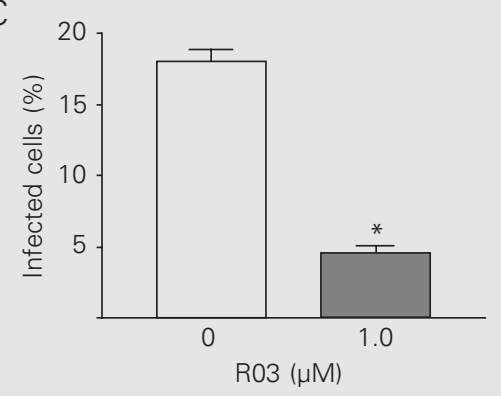

D

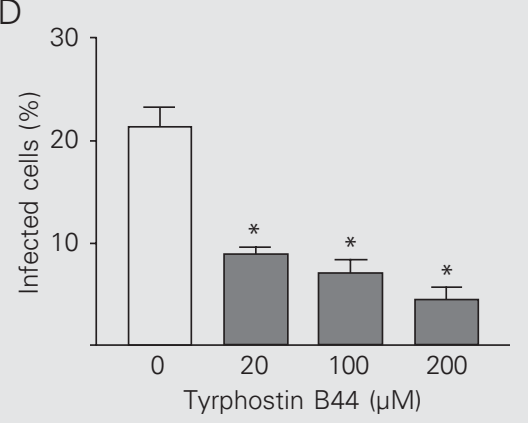

E

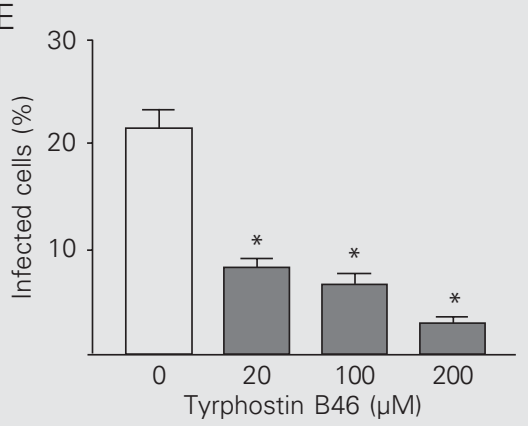

Figure 1. Effect of kinase inhibitors on Plasmodium chabaudi cell cycle development in vitro. $A$, Genistein; $B$, staurosporine; $C$, R03; $D$, tyrphostin B44, and E, tyrphostin B46. The bars indicate the percentage of infected red blood cells per 1000 cells after 17-h incubation. Results are reported as means \pm SEM for three independent experiments. ${ }^{*} P<0.001$ compared to control (one-way ANOVA and Newman-Keuls test). 
(7) and PfKIN (3). This group of kinases also includes PfPK2, and the high expression levels of this kinase at the trophozoite stage in $P$. falciparum argues for a role of this enzyme in the growth of the parasites (8).

Unraveling the basis of signaling processes in Plasmodium development within host cells might open new avenues for therapies for the disease since the increase in the drug resistance phenomenon has limited the use of the best known antimalarial drug chloroquine. A clear picture of the problem of drug resistance is missing, since the mechanism involved in drug resistance is still a matter of debate.

In the present report we have shown that protein kinase inhibitors interrupt the bloodstage cycle of the rodent malaria parasite, $P$. chabaudi, thus clearly suggesting that phosphorylations are required for normal development of these parasites. Future work should establish whether these inhibitors block signaling pathways necessary for invasion, maturation, or both, during the asexual stage. Previous work by Ward et al. (19) on $P$. knowlesi and by Dluzewski and Garcia (20) on $P$. falciparum showed that staurosporine inhibits Plasmodium entry into RBC. In $P$. falciparum tyrphostin B46 was also shown to inhibit the invasion process (20).

\section{Acknowledgments}

We thank Prof. Walter Gratzer (Medical Research Council Muscle and Cell Motility Unit, Randall Institute, King's College, London, UK) for critically reading the manuscript, and Prof. Louis Mahadevan (Nuclear Signalling Laboratory, Department of Biochemistry, University of Oxford, London, UK) for kindly supplying several kinase inhibitors.

\section{References}

1. Hotta C, Gazarini ML, Beraldo FH, Varotti FP, Lopes C, Markus RP, Pozzan T \& Garcia CRS (2000). Calcium-dependent modulation by melatonin of the circadian rhythm in malarial parasites. Nature Cell Biology, 2: 466-468.

2. Gazarini ML, Thomas AP, Pozzan T \& Garcia CRS (2003). Calcium signaling in a low calcium environment: how the intracellular malaria parasite solves the problem. Journal of Cell Biology, 161: 103110.

3. Kappes B, Doerig CD \& Graeser R (1999). An overview of Plasmodium protein kinases. Parasitology Today, 15: 449-454.

4. Doerig CD, Doerig C, Horrocks P, Coyle J, Carlton J, Sultan A, Arnot D \& Carter R (1995). Pfcrk-1, a developmentally regulated cdc-2related protein kinase of Plasmodium falciparum. Molecular and Biochemical Parasitology, 70: 167-174.

5. Graeser R, Kury P, Franklin RM \& Kappes B (1997). Characterization of mitogen-activated protein (MAP) kinase from Plasmodium falciparum. Molecular Microbiology, 23: 151-159.

6. Zhao Y, Kappes B \& Franklin RM (1993). Gene structure and expression of an unusual protein kinase from Plasmodium falciparum homologous at its carboxyl terminus with the EF hand calciumbinding proteins. Journal of Biological Chemistry, 268: 4347-4354.

7. Farber PM, Graeser R, Franklin RM \& Kappes B (1997). Molecular cloning and characterization of a second calcium-dependent protein kinase of Plasmodium falciparum. Molecular and Biochemical Parasitology, 87: 211-216.

8. Zhao Y, Kappes B, Yang J \& Franklin RM (1992). Molecular cloning, stage-specific expression and cellular distribution of a putative protein kinase from Plasmodium falciparum. European Journal of Biochemistry, 207: 305-313.
9. Saito-lto A, He S, Kimura M, Matsumura T \& Tanabe K (1995). Cloning and structural analysis of the gene for CAMP-dependent protein kinase catalytic subunit from Plasmodium yoelli. Biochimica et Biophysica Acta, 1269: 1-5.

10. Chishti AH, Maalouf GJ, Shirin M, Palek J, Wang W, Fisher D \& Liu S-C (1994). Phosphorylation of protein 4.1 in Plasmodium falciparum-infected human red blood cells. Blood, 83: 3339-3345.

11. Rangachari K, Dluzewski A, Wilson RJ \& Gratzer WB (1986). Control of malarial invasion by phosphorylation of the host cell membrane cytoskeleton. Nature, 324: 364-365.

12. Akiyama $T$, Ishida J, Nakagawa $S$, Ogawara $H$, Watanabe $S$, Itoh $N$, Shibuya M \& Fukami $Y$ (1987). Genistein, a specific inhibitor of tyrosine-specific protein kinases. Journal of Biological Chemistry, 262: 5592-5595.

13. Hidaka H \& Kobayashi $R$ (1992). Pharmacology of protein kinase inhibitors. Annual Review of Pharmacology and Toxicology, 32: 377397.

14. Read LK \& Mikkelsen RB (1990). Cyclic AMP- and Ca ${ }^{2+}$-dependent protein kinases in Plasmodium falciparum. Experimental Parasitology, 71: 39-48.

15. Robson KJ \& Jennings MW (1991). The structure of the calmodulin gene of Plasmodium falciparum. Molecular and Biochemical Parasitology, 46: 19-34.

16. Rawlings DJ \& Kaslow DC (1992). A novel 40-kDa membraneassociated EF-hand calcium-binding protein in Plasmodium falciparum. Journal of Biological Chemistry, 267: 3976-3982.

17. Garcia CRS (1999). Calcium homeostasis and signaling in the bloodstage malaria parasite. Parasitology Today, 15: 488-491.

18. Garcia CRS, Dluzewski AR, Catalani LH, Burting R, Hoyland J \& 
Mason WT (1996). Calcium homeostasis in intraerythrocytic malaria parasites. European Journal of Cell Biology, 71: 409-413.

19. Ward GE, Fujioka H, Aikawa M \& Miller LH (1994). Staurosporine inhibits invasion of erythrocytes by malarial merozoites. Experimen- tal Parasitology, 79: 480-487.

20. Dluzewski AR \& Garcia CRS (1996). Inhibition of invasion and intraerythrocytic development of Plasmodium falciparum by kinase inhibitors. Experientia, 52: 621-623. 